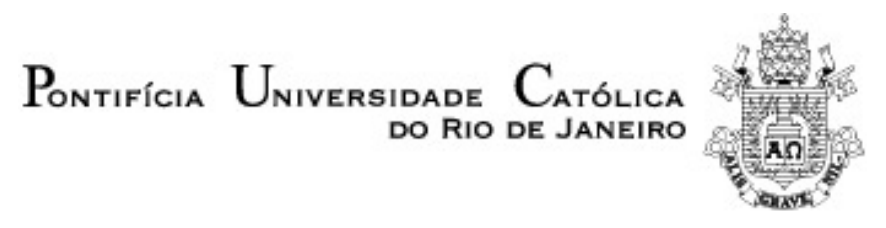

Bruno Lyons Ottoni Vaz

\title{
Efeito do Programa Bolsa Escola Sobre as Despesas das \\ Famílias
}

Dissertação de Mestrado

Dissertação apresentada como requisito parcial para obtenção do título de Mestre pelo Programa de Pós-Graduação em Economia da PUC-Rio.

Orientador: Juliano Junqueira Assunção

Rio de Janeiro, março de 2006 


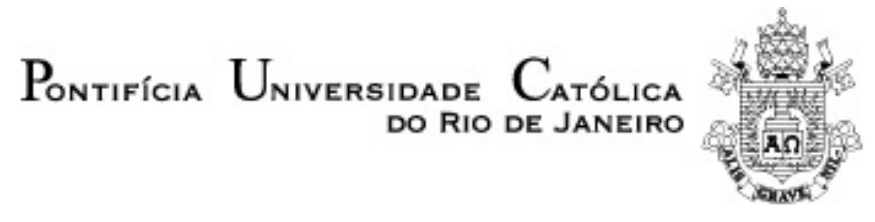

Bruno Lyons Ottoni Vaz

\title{
Efeito do Programa Bolsa Escola Sobre as Despesas das
}

Famílias

\begin{abstract}
Dissertação apresentada como requisito parcial para obtenção do título de Mestre pelo Programa de PósGraduação em Economia da PUC-Rio. Aprovada pela Comissão Examinadora abaixo assinada.
\end{abstract}

\section{Juliano Junqueira Assunção Orientador}

Departamento de Economia PUC-Rio

Gustavo Gonzaga

Departamento de Economia PUC-Rio

\section{Luis Braido EPGE/FGV}

João Pontes Nogueira

Coordenador(a) Setorial do Centro de Ciências Sociais - PUC-Rio

Rio de Janeiro, 09 de março de 2006 
Todos os direitos reservados. É proibida a reprodução total ou parcial do trabalho sem autorização da universidade, do autor e do orientador.

Bruno Lyons Ottoni Vaz

Graduou-se em Economia pela Universidade Federal do Rio de Janeiro em 2004. Cursou o Mestrado em Economia da Pontifícia Universidade Católica do Rio de Janeiro de 2004 a 2006.

Ficha Catalográfica

Vaz, Bruno Lyons Ottoni

Efeito do programa bolsa escola sobre as despesas das famílias / Bruno Lyons Ottoni Vaz; orientador: Juliano Junqueira Assunção. - Rio de Janeiro: PUC, Departamento de Economia, 2006.

49 f. ; $30 \mathrm{~cm}$

Dissertação (mestrado) - Pontifícia Universidade Católica do Rio de Janeiro, Departamento de Economia.

Inclui referências bibliográficas.

1. Economia - Teses. 2. Bolsa Escola. 3. Despesas Familiares. 4. Avaliação de Programas. I. Assunção, Juliano Junqueira. II. Pontifícia Universidade Católica do Rio de Janeiro. Departamento de Economia. III. Título

CDD: 330 


\section{Agradecimentos}

Agradeço aos meus familiares por terem despertado em mim, nas inúmeras reuniões de família, a vontade de pesquisar. Estiveram nessas reuniões meu pai, minha mãe, minha irmã, meu avô, minha prima Samantha, minha tia Tereza Cristina, meu tio Fausto, meu tio Fernando, minha tia Márcia, minha tia Valéria e muitos outros. Nessas mesmas reuniões sentiu-se a ausência dos meus primos Thiago, Aline, e Débora, de minha tia Mônica e de meu tio Antônio Carlos.

Aos meus pais, pelo apoio e incentivo fornecido em todos esses anos.

À minha esposa, por ter me incentivado a estudar sempre, mesmo quando o estudo significava a minha ausência.

Aos meus amigos de mestrado, principalmente a Lívio Ribeiro, Rodrigo Melo, Daniel Da Mata (que transferiu-se para a UNB) e a Ricardo Fibe.

Às minhas amigas de graduação Fernanda Cabral, Ana Carolina Marzulo, Mariana Ennes, Débora Duque Estrada e Joana Naritome.

Ao meu orientador, que me ensinou a fazer pesquisa empírica. 


\section{Resumo}

Lyons Ottoni Vaz, Bruno. Efeito do Programa Bolsa Escola Sobre as Despesas das Famílias. Rio de Janeiro, 2006. 49p. Dissertação de Mestrado - Departamento de Economia, Pontifícia Universidade Católica do Rio de Janeiro.

Esse artigo realiza um estudo dos efeitos do Programa Bolsa Escola Federal sobre as despesas das famílias. A base de dados utilizada foi a Pesquisa dos Orçamentos Familiares (POF), que por tratar de forma detalhada das despesas das famílias e por fornecer o valor recebido pelas famílias do Programa Bolsa Escola Federal, propicia uma excelente oportunidade de responder a questão referente ao destino do dinheiro recebido do programa. O principal resultado é que famílias que recebem a bolsa do Programa Bolsa Escola tendem a gastar mais em alimentos e não reduzem seus gastos em educação.

\section{Palavras-chave}

Bolsa Escola; Despesas Familiares; Avaliação de Programas 


\section{Abstract}

Lyons Ottoni Vaz, Bruno. Effect of the Bolsa Escola Program on Household Expenditures. Rio de Janeiro, 2006. 49p. Dissertation Departamento de Economia, Pontifícia Universidade Católica do Rio de Janeiro.

This article studies the effects of the Brazilian conditional cash transfer program, the Bolsa Escola Federal, on household expenditures. The dataset used was a survey of household budgets (Pesquisa dos Orçamentos Familiares), which, in providing detailed information regarding family expenditures and the value households received through the Bolsa Escola Federal Program, offers an excellent opportunity to answer the question concerning the destination of the money received through the program. The main result of the article is that households receiving the grant from the program tend to spend more on food and do not reduce their expenditures on education.

\section{Keywords}

Conditional Cash Transfers; Household Expenditures; Program Evaluation 


\section{Sumário}

1 Introdução 9

2 O Programa Bolsa Escola Federal 12

3 Revisão da Literatura 14

4 Descrição dos Dados 20

5 Análise dos Gastos Baseada nas Categorias de Despesa 24

$\begin{array}{ll}6 \text { Identificação } & 28\end{array}$

$\begin{array}{lll}7 \text { Conclusão } & 37\end{array}$

8 Referências Bibliográficas 38

9 Apêndice $\quad 42$ 


\section{Lista de figuras e tabelas}

Figura 1 - Identificação Estilizada 42

Tabela 1 - Categorias de despesa e sua composição 43

Tabela $2 \mathrm{a}$ - Composição das categorias de despesa total com alimentos para casa e artigos de limpeza doméstica

Tabela $2 \mathrm{~b}$ - Composição das categorias de despesa total com produtos de higiene corporal para uso coletivo e com bebidas alcoólicas

Tabela 3 - Composição das categorias de despesa total em educação

Tabela 4 - Estatísticas Descritivas

Tabela 5 - Porcentagem das famílias elegíveis que têm despesa positiva nas categorias da tabela 2

Tabela 6 - Porcentagem das famílias elegíveis que têm despesa positiva nas categorias da tabela 3

Tabela 7 - Vetor de controles

Tabela 8 - Avaliando o perfil das despesas das famílias elegíveis nas categorias da tabela 1

Tabela 9 - Avaliando o perfil das despesas das famílias elegíveis nas categorias da tabela 2

Tabela 10 - Avaliando o perfil das despesas das famílias elegíveis nas categorias da tabela 3

Tabela 11 - Identificação dos coeficientes obtidos na tabela 8

Tabela 12 - Identificação dos coeficientes obtidos na tabela 9

Tabela 13 - Identificação dos coeficientes obtidos na tabela 10 